\title{
Release of Hypocretin (Orexin) during Waking and Sleep States
}

\author{
Lyudmila I. Kiyashchenko, ${ }^{1,2,3 *}$ Boris Y. Mileykovskiy,,${ }^{1,2,3 *}$ Nigel Maidment, ${ }^{1}$ Hoa A. Lam, ${ }^{1}$ Ming-Fung Wu, ${ }^{1,2}$ \\ Joshi John, ${ }^{1,2}$ John Peever, ${ }^{1,2}$ and Jerome M. Siegel ${ }^{1,2}$ \\ ${ }^{1}$ Department of Psychiatry and Biobehavioral Sciences and Brain Research Institute, University of California Los Angeles \\ School of Medicine, and 2Veterans Administration of Greater Los Angeles Healthcare System-Sepulveda, North Hills, \\ California 91343, and 3/nstitute of Evolutionary Physiology and Biochemistry, Russian Academy of Science, St. \\ Petersburg, 194223, Russia
}

Hypocretin (Hcrt or orexin) somas are located in the hypothalamus and project widely to forebrain and brainstem regions, densely innervating monoaminergic and cholinergic cells. Loss of Hcrt function results in the sleep disorder narcolepsy. However, the normal pattern of Hcrt release across the sleep-wake cycle is unknown. We monitored Hcrt-1 release in the basal forebrain, perifornical hypothalamus, and locus ceruleus (LC) across the sleep-wake cycle using microdialysis in freely moving cats and a sensitive solid phase radioimmunoassay. We found that the peptide concentration in dialysates from the hypothalamus was significantly higher during active waking (AW) than during slow-wave sleep (SWS). Moreover, Hcrt-1 release was significantly higher during rapid eye movement
(REM) sleep than during SWS in the hypothalamus and basal forebrain. We did not detect a significant difference in release across sleep-waking states in the LC, perhaps because recovered levels of the peptide were lower at this site. Because there was a trend toward higher levels of Hcrt-1 release during AW compared with quiet waking $(\mathrm{QW})$ in our 10 min dialysis samples, we compared Hcrt-1 levels in CSF in $2 \mathrm{hr}$ AW and QW periods. Hcrt-1 release into CSF was $67 \%$ higher during AW than during QW. Elevated levels of Hcrt during REM sleep and AW are consistent with a role for Hcrt in the central programming of motor activity.

Key words: hypocretin; orexin; microdialysis; sleep-waking cycle; motor activity; cataplexy
Hypocretin (Hcrt) peptides are synthesized by a small number of neurons in the perifornical and lateral hypothalamus (De Lecea et al., 1998; Sakurai et al., 1998). These neurons have dense projections to the basal forebrain (BF), limbic structures, and brainstem regions, in particular those related to waking and rapid eye movement (REM) sleep regulation (Peyron et al., 1998; Nambu et al., 1999). Symptoms resembling those seen in human narcolepsy are seen in prepro-hypocretin null mutant mice, in dogs with a mutation in one of the two Hcrt receptors, and in rats with targeted destruction of Hcrt receptor-expressing neurons (Chemelli et al., 1999; Lin et al., 1999; Gerashchenko et al., 2001). Human narcolepsy is linked to an $85-95 \%$ loss of Hcrt neurons (Thannickal et al., 2000) and undetectable Hcrt levels (Peyron et al., 2000). Narcolepsy has long been thought to be a disease affecting REM sleep regulation because of the similarity of cataplexy and sleep paralysis to the muscle-tone suppression of REM sleep, the narcoleptic's short REM sleep latency, hypnagogic hallucinations that resemble dreaming (Rechtschaffen and Dement, 1967), and similarities of locus ceruleus (LC) and medial medullary unit discharge during cataplexy and REM sleep (Siegel et al., 1991; Wu et al., 1999).

Two hypotheses have been proposed for the pattern of release of Hcrt across the sleep-wake cycle. One hypothesis is influenced

\footnotetext{
Received Feb. 27, 2002; revised April 4, 2002; accepted April 9, 2002.

This work was supported by National Institutes of Health Grants MH64109 and NS14610 and by the Medical Research Service of the Department of Veterans Affairs.

*L.I.K. and B.Y.M., contributed equally to this study.

Correspondence should be addressed to Jerome Siegel, Department of Psychiatry, University of California Los Angeles, Neurobiology Res. 151A3, Veterans Adminstration of Greater Los Angeles Healthcare System, 16111 Plummer Street, North Hills, CA 91343. E-mail: JSiegel@UCLA.edu.

Copyright (C) 2002 Society for Neuroscience $0270-6474 / 02 / 225282-05 \$ 15.00 / 0$
}

by the finding that noradrenergic, serotonergic, and histaminergic neurons that are strongly innervated by Hcrt neurons have a "REM sleep-off" activity profile (Vanni-Mercier et al., 1984; Jacobs, 1987; Wu et al., 1999) and the finding that Hcrt is excitatory to aminergic cell groups (Hagan et al., 1999; Ivanov and Aston-Jones, 2000; Brown et al., 2001; Eriksson et al., 2001). This hypothesis postulates maximal Hcrt release during waking, reduced release during slow-wave sleep (SWS), and minimal release during REM sleep (Hungs and Mignot, 2001). The other hypothesis, influenced by the finding that cholinergic cells are also strongly innervated and excited by Hcrt neurons (Burlet et al., 2002) and by the increased activity in cholinergic neuronal populations during waking and REM sleep (Steriade et al., 1990; Sakai and Onoe, 1997) suggests that Hcrt release is maximal during REM sleep and during waking and is minimal during SWS (Kilduff and Peyron, 2000).

It has been difficult to determine the pattern of release of Hcrt because the limited sensitivity of the assays used has required very long duration microdialysis samples. This has prevented investigators from separating the contributions of REM sleep, SWS, and waking behavior to Hcrt levels. In the current study, we have addressed this problem by adapting a sensitive solid-phase peptide assay for Hcrt measurement (Maidment and Evans, 1991) and by using cats, which have longer-duration sleep periods than rodents, as subjects.

\section{MATERIALS AND METHODS}

Surgery. All procedures were approved by the Animal Studies Committee of the Sepulveda Veterans Administration Medical Center/University of California Los Angeles, in accordance with United States Public Health Service guidelines. Aseptic stereotaxic neurosurgery was performed on 
four young cats (two males and two females) weighing from 2.5 to $3.5 \mathrm{~kg}$. Animals were intubated, and deep anesthesia was maintained with $2 \%$ isoflurane. Surface and depth electrodes $(n=8)$ were implanted to record sleep- and waking-state physiology, using stereotaxic coordinates from the atlas of Snider and Neimer (1961). Stainless-steel screws were threaded into the bone over the left frontal cortex [anterior (A), 4; lateral $(\mathrm{L}), 8]$ to record cortical EEG and also over the orbit in the frontal sinus to register electrooculograms. Stainless-steel wires were inserted into the dorsal neck musculature to record splenius electromyograms. Depth electrodes with $0.5 \mathrm{~mm}$ deinsulated tips were inserted bilaterally to record activity in the lateral geniculate nucleus [A, 6; L, 10; height $(\mathrm{H})$, $+2.3]$.

For microdialysis, guide cannulas (NG-35; Eicom, Kyoto, Japan) were bilaterally implanted $5 \mathrm{~mm}$ above target sites in the BF, perifornical hypothalamus (HYP), and LC. Coordinates of the sampling sites were as follows: for the BF, A, 14; L, 5; and $\mathrm{H},-4.5$; for the HYP, A, 11; L, 2; and $\mathrm{H},-3.5$; and for the $\mathrm{LC}$, posterior $(\mathrm{P}), 2.5 ; \mathrm{L}, 2.5$; and $\mathrm{H},-2.5$. A minimum of 2 weeks postoperative recovery was allowed.

Microdialysis sampling. Animals were adapted to the recording chamber for $24 \mathrm{hr}$ before baseline polygraphic recordings of sleep-wake cycles. Simultaneous sleep recording and collection of Hcrt-1 microdialysis samples were started at least $12 \mathrm{hr}$ after the insertion of each microdialysis probe (NDP-35-015; Eicom) $(1000 \mathrm{kDa}$; membrane length, $1.5 \mathrm{~mm}$; outer diameter, $0.6 \mathrm{~mm}$; recovery rate, $\geq 20 \%$ ). Dialysates were collected from each probe for $2 \mathrm{~d}$. Dialysis probes were perfused with artificial CSF (Harvard Apparatus, Holliston, MA) in a push-pull manner using a microsyringe pump (ESP-64; Eicom) with samples collected into a $20 \mu \mathrm{l}$ manual sample injector (model 9725I; Eicom) at $2 \mu \mathrm{l} / \mathrm{min}$. A $2 \mathrm{hr}$ stabilization period was used before sampling. Dialysates were collected in $10 \mathrm{~min}(20 \mu \mathrm{l})$ samples during temporally adjacent periods of active waking (AW), quiet waking (QW), SWS, and REM sleep to control for any circadian effects or slow changes in recovery from the probe. States with a duration that was $<75 \%$ of the $10 \mathrm{~min}$ sample period were excluded from analysis. Hcrt-1 levels in samples that were $>75 \%$ complete were extrapolated to a 10 min duration. Data from one BF probe was excluded because of a $>40$-fold difference in detected Hcrt levels between the $2 \mathrm{~d}$. Hcrt- 1 levels in all other probes deviated by less than a factor of 3 between days 1 and 2 .

CSF collection and motor activity. CSF $(0.5 \mathrm{ml})$ was drawn from the cisterna magna in six cats with a 22 gauge spinal needle after fluothane anesthesia. CSF samples underwent a reversed-phase extraction procedure before radioimmunoassay (RIA) analysis. All CSF collections were done at 11:00 A.M. within 3-5 min after $2 \mathrm{hr}$ of alert QW or $2 \mathrm{hr}$ of AW during which the experimenter encouraged the cat to play and locomote. Motor activity was measured with Mini-Mitter actigraphs (Actiwatch; MiniMitter Inc, Sundriver, OR) placed in a neck collar. The two sets of observations in each subject were conducted on adjacent days in counterbalanced order.

Radioimmunoassay. Microdialysate samples were analyzed directly by RIA. Samples were acidified with $1 \%$ trifluoroacetic acid (TFA) and loaded onto a C18 Sep-Column (Waters Corp., Milford, MA). The peptide was eluted with $1 \%$ TFA $/ 40 \%$ acetonitrile. The eluant was then dried down and resuspended in RIA buffer before assay. The Hcrt-1, iodinated Hcrt-1, and Hcrt-1 antiserum were obtained from Phoenix Pharmaceuticals, Inc., \#RK-003-30 (Belmont, CA). Hcrt-1 and Hcrt-2 are cleaved from the same precursor peptide and are generally thought to be found in the same neurons (De Lecea et al., 1998; Sakurai et al., 1998). Hcrt-2 is much less stable than Hcrt-1 and was not measured in the current study. The solid-phase assay (Maidment and Evans, 1991) provided an $\mathrm{IC}_{50}$ of $3.8 \pm 0.7 \mathrm{fmol}$ and a limit of detection of $\sim 0.2 \mathrm{fmol}$.

Histology and data analysis. At the end of the study, animals were anesthetized with Nembutal $(35 \mathrm{mg} / \mathrm{kg}$, i.v.) and perfused intracardially with saline followed with buffered $10 \%$ formalin. Brain tissues were cut into 50- $\mu \mathrm{m}$-thick sections. Two-way ANOVA, Tukey's test, and paired $t$ test were used for sample analysis. We present mean values \pm SEM.

\section{RESULTS}

Microdialysis samples were collected from sites in the HYP (Fig. $1 A$ ), an area containing a high concentration of Hcrt somas; the BF (Fig. 1B), an area with wake-REM sleep-active cholinergic neurons, sleep-active neurons, and dense Hcrt innervation (Szymusiak, 1995; Peyron et al., 1998; Nambu et al., 1999); and the LC (Fig. 1C), a brainstem noradrenergic nucleus with strong Hcrt innervation (Peyron et al., 1998). Hcrt-1 release differed signifi-
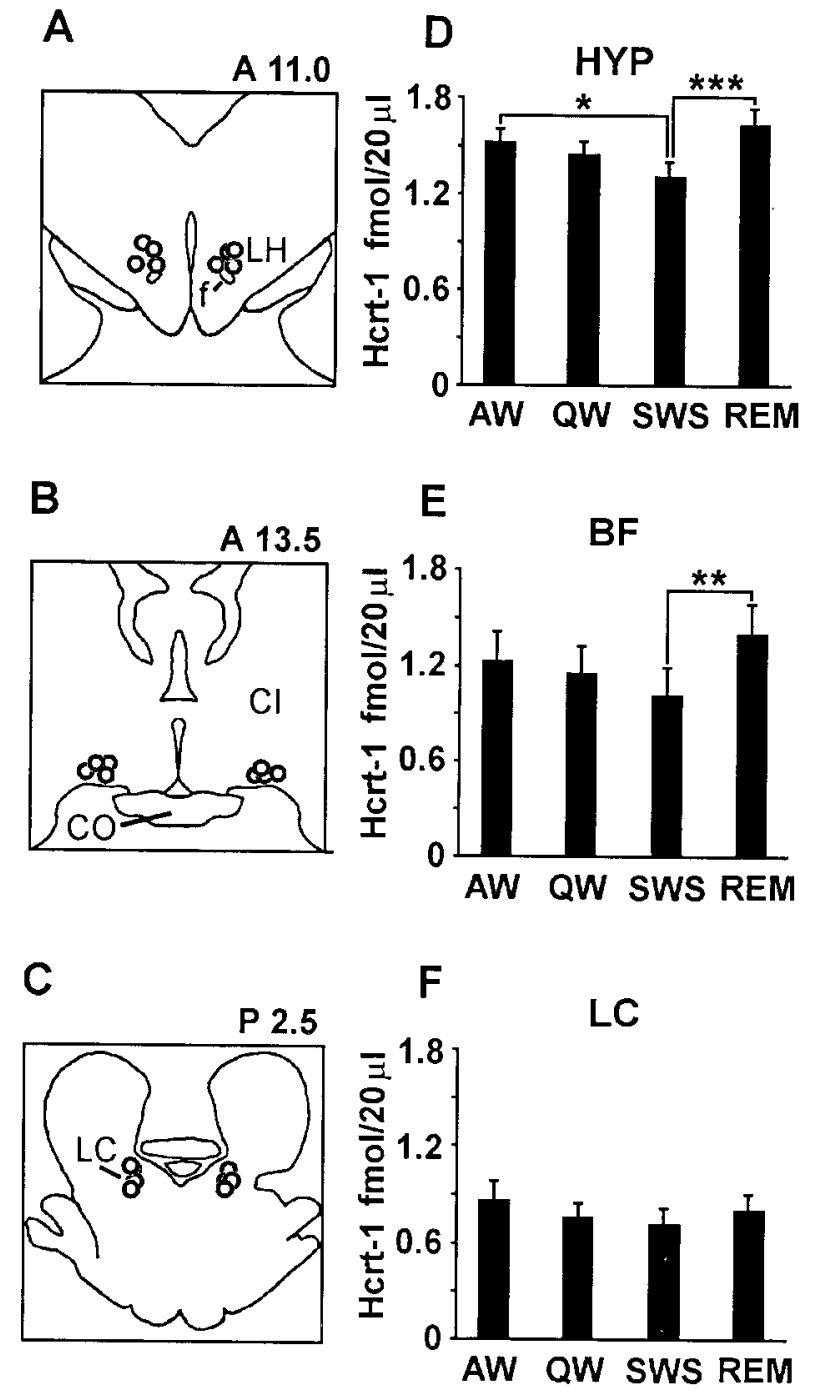

Figure 1. Sleep-cycle release of Hcrt. $A-C$, Location of the tips of dialysis probes in the HYP, BF, and LC. $C I$, Internal capsule; $C O$, optic chasm; $f$, fornix; $L H$, lateral hypothalamus. $D-F$, Hcrt levels across the sleep-waking states in the HYP, BF, and LC. Sleep-state values differ as a function of state (HYP, $p<0.003, F=4.7$, df $=3254$; BF, $p<0.03, F=$ 3.2 , df $=3133$ ). Tukey's test; ${ }^{*} p<0.05$; ${ }^{* *} p<0.02 ;{ }^{* *} p<0.002$. Hert release is maximal during AW and REM sleep and minimal during SWS and QW in the HYP and BF.

cantly in the HYP as a function of sleep-waking state $(p<0.003$; $F=4.7$; df $=3,254)$ (Fig. $1 D)$ and in the $\mathrm{BF}(p<0.03 ; F=3.2$; $\mathrm{df}=3,133$ ) (Fig. 1E). Overall levels of Hcrt-1 recovered in the LC were lower than those in the HYP and BF, and the changes across sleep-waking states in the LC were not significant $(p<$ $0.7 ; F=0.46 ; \mathrm{df}=3,161$ ) (Fig. $1 F)$. The lower levels of Hcrt-1 recovered from the LC may be attributable to its smaller size and proximity to the fourth ventricle, making for a poorer seal around the probe. Levels during REM sleep were significantly elevated relative to SWS levels in the HYP ( $p<0.002$; Tukey's test) and $\mathrm{BF}$ ( $p<0.02$; Tukey's test) regions. Hcrt-1 levels during AW were significantly higher than those during SWS in the HYP $(p<$ 0.05; Tukey's test). Hcrt-1 levels during REM sleep did not significantly differ from those during AW in any of the sampled regions. Figure 2 shows an individual hypnogram from the HYP demonstrating the elevated levels of Hcrt-1 in dialysates taken 
Figure 2. Hypnogram $(A)$ and Hcrt levels $(B)$ in the HYP across the sleep cycle. Circles indicate points at which dialysate was taken. Hcrt levels are maximal after long AW and REM sleep periods and minimal after SWS periods.

after REM sleep or AW periods relative to the levels taken after QW or SWS periods.

Because we saw a trend toward increased Hcrt-1 levels in our 10 min microdialysis samples during AW relative to QW (Fig. 1), we investigated the effect of a more prolonged AW period on overall brain release of Hcrt-1 into CSF. In an independent group of six cats, we sampled CSF for Hcrt-1 after $2 \mathrm{hr}$ periods of QW and 2 hr periods of AW. The Hcrt-1 concentration in CSF was increased during AW relative to QW ( $p<0.02 ; t=3.4$; df $=5$; paired $t$ test) by a mean of $67 \%$ (Fig. 3).

\section{DISCUSSION}

We find maximal Hcrt-1 release in the HYP and BF during both REM sleep and AW and minimal release during SWS. Our findings support the model of Hcrt release put forth by Kilduff and Peyron (2000). It has been reported recently that approximately one-half of the neurons located in the perifornical HYP are active during both wakefulness and REM sleep, whereas another cell population in this region has a REM sleep-off discharge profile (Alam et al., 2002). The current results suggest that the REM-waking active population includes Hcrt-containing cells. The widely ramifying projection pattern of individual Hcrt neurons (Peyron et al., 1998; Abrahamson and Moore, 1999; Nambu et al., 1999) suggests that Hcrt release may be similar in all brain regions, but we cannot exclude the possibility that presynaptic regulation or other mechanisms could produce differing local release.

Torterolo et al. (2001) reported that significant c-fos expression in Hcrt-containing cells is detected during both AW and the carbachol induced REM sleep-like state. In contrast, Estabrooke et al. (2001) reported a negative correlation between c-fos expression in Hcrt cells and amounts of natural REM and SWS. However, the c-fos method has insufficient temporal resolution for studies of short-duration processes such as natural REM sleep (Cirelli and Tononi, 2000). Higher levels of Hcrt-1 have been seen during the waking portion of the circadian cycle compared with radioimmunoassay of long samples that included REM and SWS (Taheri et al., 2000; Fujiki et al., 2001; Yoshida et al., 2001). Our current results demonstrate that, although overall levels of Hcrt are lower at times of the day when sleeping and inactivity predominate, levels within sleep are not homogeneous, with REM sleep being correlated with high levels of release and SWS with low levels of release in the BF and HYP.

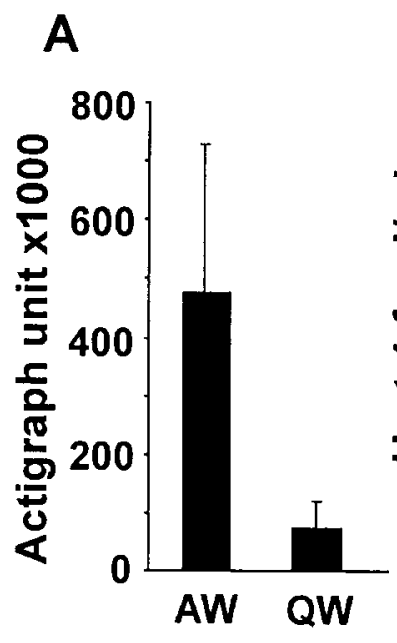

B

Figure 3. Concentrations of Hcrt-1 in the CSF during AW and QW. Left, Actigraph readings reflect greater levels of head movement during active waking. Right, Hcrt levels are significantly higher in CSF taken after a 2 hr AW period than after a $2 \mathrm{hr}$ QW period. ${ }^{* *} p<0.02 ; t=3.4$; $\mathrm{df}=5$.

We also found significantly higher levels of Hcrt-1 release during AW compared with QW in our CSF samples (Fig. 3). Thus the level of Hcrt-1 is not simply dependent on the electroencephalographically defined waking state or circadian time, but may reflect the intensity of motor system activation. Central motor systems reach discharge levels equal to or greater than those of active waking during REM sleep and have minimal discharge during SWS (Evarts, 1964; Siegel and Tomaszewski, 1983; Siegel et al., 1983; Siegel, 2000)

The well known link between motor activity and alertness (Bachmann and Grill, 1987; Vuori et al., 1988; Offenbacher and Stucki, 2000; Kruk et al., 2001) may be a factor in the narcolepsy syndrome. Motor activity, mediated by descending systems, is normally coordinated with excitation of ascending activating systems in the brain. Our results suggest that Hcrt neurons play a critical role in this coordination through the activation of cholinergic and aminergic systems during waking. The absence of Hcrt peptides could cause the impaired maintenance of waking that is characteristic of narcolepsy.

The finding of high levels of Hcrt-1 release during REM sleep 
in the HYP and BF will have to be integrated into models of REM sleep regulation. If, as the anatomy suggests might be the case, this pattern of release holds for noradrenergic, serotonergic, and histaminergic neurons innervated by Hcrt neurons (Peyron et al., 1998; Nambu et al., 1999), this release pattern then would appear inconsistent with the silence of these neurons during REM sleep (Vanni-Mercier et al., 1984; Jacobs, 1987; Wu et al., 1999). Hcrt is excitatory to these cell groups (Hagan et al., 1999; Ivanov and Aston-Jones, 2000; Brown et al., 2001; Eriksson et al., 2001). However, Hcrt excitation of aminergic neurons during REM sleep could be blocked by simultaneous GABAergic inhibition or glutamatergic disfacilitation from other sources. Alternatively, Hcrt peptides, which can produce increases in both GABA and glutamate release (van den Pol et al., 1998), could produce a relatively selective potentiation of GABA release during REM sleep, a time when increased levels of GABA are being released onto these cell groups (Nitz and Siegel, 1996, 1997a,b).

Narcolepsy is characterized by sudden losses of muscle tone during waking (cataplexy) and at sleep onset and offset (sleep paralysis). These symptoms suggest that Hcrt peptides may have a role in the maintenance of muscle tone. Intracerebroventricular administration of Hcrt (Hagan et al., 1999) facilitates motor activity in freely moving rats, and microinjections of this peptide in the vicinity of the LC during waking and in decerebrate rats increases LC discharge and muscle tone (Bourgin et al., 2000; Kiyashchenko et al., 2001). The elevated Hcrt-1 release during AW suggests a role for this peptide in the further facilitation of motor output.

\section{REFERENCES}

Abrahamson EE, Moore RY (1999) Topographical organization of efferent projections arising from hypocretin containing neuron populations located in the lateral hypothalamus. Soc Neurosci Abstr 25:1886.

Alam MN, Gong H, Alam T, Jaganath R, McGinty D, Szymusiak R (2002) Sleep-waking discharge patterns of neurons recorded in the rat perifornical lateral hypothalamic area. J Physiol (Lond) 538:619-631.

Bachmann GA, Grill J (1987) Exercise in the postmenopausal woman. Geriatrics 42:75-77, 81-85.

Bourgin P, Huitron-Resendiz S, Spier AD, Fabre V, Morte B, Criado JR, Sutcliffe JG, Henriksen SJ, De Lecea L (2000) Hypocretin-1 modulates rapid eye movement sleep through activation of locus ceruleus neurons. J Neurosci 20:7760-7765.

Brown RE, Sergeeva O, Eriksson KS, Haas HL (2001) Orexin A excites serotonergic neurons in the dorsal raphe nucleus of the rat. Neuropharmacology 40:457-459.

Burlet S, Tyler CJ, Leonard CS (2002) Direct and indirect excitation of laterodorsal tegmental neurons by hypocretin/orexin peptides: implications for wakefulness and narcolepsy. J Neurosci 22:2862-2872.

Chemelli RM, Willie JT, Sinton C, Elmquist J, Scammell T, Lee C, Richardson J, Williams S, Xiong Y, Kisanuki Y, Fitch T, Nakazato M, Hammer R, Saper C, Yanagisawa M (1999) Narcolepsy in orexin knockout mice: molecular genetics of sleep regulation. Cell 98:437-451.

Cirelli C, Tononi G (2000) On the functional significance of c-fos induction during the sleep-waking cycle. Sleep 23:453-469.

De Lecea L, Kilduff T, Peyron C, Gao XB, Foye PE, Danielson PE, Fukahara C, Battenberg ELF, Gautvik VT, Barlett FS, Frankel WN, van den Pol AN, Bloom F, Gautvik KM, Sutcliffe JG (1998) The hypocretins: hypothalamus-specific peptides with neuroexcitatory activity. Proc Natl Acad Sci USA 95:322-327.

Eriksson KS, Sergeeva O, Brown RE, Haas HL (2001) Orexin/hypocretin excites the histaminergic neurons of the tuberomammillary nucleus. J Neurosci 21:9273-9279.

Estabrooke IV, McCarthy MT, Ko E, Chou TC, Chemelli RM, Yanagisawa M, Saper CB, Scammell TE (2001) Fos expression in orexin neurons varies with behavioral state. J Neurosci 21:1656-1662.

Evarts EV (1964) Temporal patterns of discharge of pyramidal tract neurons during sleep and waking in the monkey. J Neurophysiol 27:152-171.

Fujiki N, Yoshida Y, Ripley B, Honda K, Mignot E, Nishino S (2001) Changes in CSF hypocretin-1 (orexin A) levels in rats across 24 hours and in response to food deprivation. NeuroReport 12:993-997.

Gerashchenko D, Kohls MD, Greco M, Waleh NS, Salin-Pascual R, Kilduff TS, Lappi DA, Shiromani PJ (2001) Hypocretin-2-saporin le- sions of the lateral hypothalamus produce narcoleptic-like sleep behavor in the rat. J Neurosci 21:7273-7283.

Hagan JJ, Leslie RA, Patel S, Evans ML, Wattam TA, Holmes S, Benham CD, Taylor SG, Routledge C, Hemmati P, Munton RP, Ashmeade TE, Shah AS, Hatcher JP, Hatcher PD, Jones DN, Smith MI, Piper DC, Hunter AJ, Porter RA, et al (1999) Orexin A activates locus coeruleus cell firing and increases arousal in the rat. Proc Natl Acad Sci USA 96:10911-10916.

Hungs M, Mignot E (2001) Hypocretin/orexin, sleep, and narcolepsy. BioEssays 23:397-408.

Ivanov A, Aston-Jones G (2000) Hypocretin/orexin depolarizes and decreases potassium conductance in locus coeruleus neurons. NeuroReport 11:1755-1758.

Jacobs BL (1987) Brain monoaminergic unit activity in behaving animals. In: Progress in psychobiology and physiological psychology (Epstein AN, Morrison AR, eds), pp 171-206. New York: Academic.

Kilduff TS, Peyron C (2000) The hypocretin/orexin ligand-receptor system: implications for sleep and sleep disorders. Trends Neurosci $23: 359-365$

Kiyashchenko LI, Mileykovskiy BY, Lai YY, Siegel JM (2001) Increased and decreased muscle tone with orexin (hypocretin) microinjections in the locus coeruleus and pontine inhibitory area. J Neurophysiol 85:2008-2016.

Kruk B, Chmura J, Krzeminski K, Ziemba AW, Nazar K, Pekkarinen H, Kaciuba-Uscilko H (2001) Influence of caffeine, cold, and exercise on multiple choice reaction time. Psychopharmacology 157:197-201.

Lin L, Faraco J, Kadotani H, Rogers W, Lin X, Qui X, de Jong P, Nishino S, Mignot E (1999) The REM sleep disorder canine narcolepsy is caused by a mutation in the hypocretin (orexin) receptor gene. Cell 98:365-376.

Maidment NT, Evans CJ (1991) Measurement of extracellular neuropeptides in the brain: microdialysis linked to solid phase radioimmunoassays with subfemtomole limits of detection. In: Microdialysis in the neurosciences (Robinson TE, Justice JB, eds), pp 275-303. New York: Elsevier.

Nambu T, Sakurai T, Mizukami K, Hosoya Y, Yanagisawa M, Goto K (1999) Distribution of orexin neurons in the adult rat brain. Brain Res 827:243-260.

Nitz D, Siegel JM (1996) GABA release in the posterior hypothalamus of the cat as a function of sleep/wake state. Am J Physiol 40:R1707-R1712.

Nitz D, Siegel JM (1997a) GABA release in the cat locus coeruleus as a function of the sleep/wake state. Neuroscience 78:795-801.

Nitz D, Siegel JM (1997b) GABA release in the dorsal raphe nucleus: role in the control of REM sleep. Am J Physiol 273:R451-R455.

Offenbacher M, Stucki G (2000) Physical therapy in the treatment of fibromyalgia. Scand J Rheumatol Suppl 113:78-85.

Peyron C, Tighe DK, van den Pol AN, De Lecea L, Heller HC, Sutcliffe JG, Kilduff TS (1998) Neurons containing hypocretin (orexin) project to multiple neuronal systems. J Neurosci 18:9996-10015.

Peyron C, Faraco J, Rogers W, Ripley B, Overeem S, Charnay Y, Nevsimalova S, Aldrich M, Reynolds D, Albin R, Li R, Hungs M, Pedrazzoli M, Padigaru M, Kucherlapati M, Fan J, Maki R, Lammers GJ, Bouras C, Kucherlapati R, et al (2000) A mutation in a case of early onset narcolepsy and a generalized absence of hypocretin peptides in human narcoleptic brains. Nat Med 6:991-997.

Rechtschaffen A, Dement W (1967) Studies on the relation of narcolepsy, cataplexy, and sleep with low voltage random EEG activity. In: Sleep and altered states of consciousness (Kety SS, Evarts EV, eds), pp 488-505. Baltimore: Williams and Wilkins

Sakai K, Onoe H (1997) Critical role for M3 muscarinic receptors in paradoxical sleep generation in the cat. Eur J Neurosci 9:415-423.

Sakurai T, Amemiya A, Ishii M, Matsuzaki I, Chemelli RM, Tanaka H, Williams SC, Richardson JA, Kozlowski GP, Wilson S, Arch JR, Buckingham RE, Haynes AC, Carr SA, Annan RS, McNulty DE, Liu WS, Terrett JA, Elshourbagy NA, Bergsma DJ, et al (1998) Orexins and orexin receptors: a family of hypothalamic neuropeptides and G protein-coupled receptors that regulate feeding behavior. Cell 92:573-585.

Siegel JM (2000) Brainstem mechanisms generating REM sleep. In: Principles and practice of sleep medicine (Kryger MH, Roth T, Dement WC, eds), pp 112-133. New York: WB Saunders.

Siegel JM, Tomaszewski KS (1983) Behavioral organization of reticular formation: studies in the unrestrained cat. I Cells related to axial, limb, eye, and other movements. J Neurophysiol 50:696-716.

Siegel JM, Tomaszewski KS, Wheeler RL (1983) Behavioral organization of reticular formation: studies in the unrestrained cat. II. Cells related to facial movements J Neurophysiol 50:717-723.

Siegel JM, Nienhuis R, Fahringer H, Paul R, Shiromani P, Dement WC, Mignot E, Chiu C (1991) Neuronal activity in narcolepsy: identification of cataplexy related cells in the medial medulla. Science 262:1315-1318.

Snider RS, Neimer WT (1961) A stereotaxic atlas of the cat brain Chicago: University of Chicago.

Steriade M, Datta S, Pare D, Oakson G, Curro D (1990) Neuronal 
activities in brain-stem cholinergic nuclei related to tonic activation processes in thalamocortical systems. J Neurosci 10:2541-2559.

Szymusiak R (1995) Magnocellular nuclei of the basal forebrain: substrates of sleep and arousal regulation. Sleep 18:478-500.

Taheri S, Sunter D, Dakin C, Moyes S, Seal L, Gardiner J, Rossi M, Ghatei M, Bloom S (2000) Diurnal variation in orexin A immunoreactivity and prepro-orexin mRNA in the rat central nervous system. Neurosci Lett 279:109-112.

Thannickal TC, Moore RY, Nienhuis R, Ramanathan L, Gulyani S, Aldrich M, Cornford M, Siegel JM (2000) Reduced number of hypocretin neurons in human narcolepsy. Neuron 27:469-474.

Torterolo P, Yamuy J, Sampogna S, Morales FR, Chase MH (2001) $\mathrm{C}$-fos expression in hypocretinergic neurons during wakefulness and carbachol-induced active sleep. Sleep 24:A155-A156.

van den Pol AN, Gao XB, Obrietan K, Kilduff TS, Belousov AB (1998)
Presynaptic and postsynaptic actions and modulation of neuroendocrine neurons by a new hypothalamic peptide, hypocretin/orexin. J Neurosci 18:7962-7971.

Vanni-Mercier G, Sakai K, Jouvet M (1984) Specific neurons for wakefulness in the posterior hypothalamus in the cat (in French). C R Acad Sci III 298:195-200.

Vuori I, Urponen H, Hasan J, Partinen M (1988) Epidemiology of exercise effects on sleep. Acta Physiol Scand Suppl 574:3-7.

Wu MF, Gulyani S, Yao E, Mignot E, Phan B, Siegel JM (1999) Locus coeruleus neurons: cessation of activity during cataplexy. Neuroscience 91:1389-1399.

Yoshida Y, Fujiki N, Nakajima T, Ripley B, Matsumura H, Yoneda H, Mignot E, Nishino S (2001) Fluctuation of extracellular hypocretin-1 (orexin A) levels in the rat in relation to the light-dark cycle and sleep-wake activities. Eur J Neurosci 14:1075-1081. 